\title{
The Influence of Positive Affect and Visual Access on the Discovery of Integrative Solutions in Bilateral Negotiation
}

\author{
Peter J. D. Carnevale \\ College of Business Administration, University of lowa
}

AND

Alice M. ISEN

Research Center for Group Dynamics, Institute for Social Research, University of Michigan

The present study investigated the influence of positive affect and visual access on the process and outcome of negotiation in an integrative bargaining task. Visual access was crossed with positive affect in a $2 \times 2$ design. The results supported the hypotheses that positive affect would reduce the use of contentious tactics and would increase joint benefit, just as had been found for the presence of a barrier that eliminated visual access to the other negotiator (S. Lewis \& W. Fry, 1977, Organizational Behavior and Human Performance 20, 75-92). This latter finding was also replicated. Only when bargainers were face to face and not in a positive state was there heavy use of contentious tactics, reduced trade-offs, and fewer integrative solutions. This means that positive affect can overcome the competitive processes and poor outcomes normally observed in face-to-face integrative bargaining. The results are discussed in terms of the cognitive dynamics of negotiation. $1986 \mathrm{Aca}$ demic Press. Inc.

Negotiation is a process by which two or more people make a joint decision with regard to an issue about which there are initial differences in preference. The present study examines the effects of positive affect and visual access on negotiation strategies and outcomes.

Successful negotiation often requires the parties to discover integrative solutions. A solution in negotiation is said to be integrative to the extent that it reconciles the parties' divergent interests and provides them high joint benefit (Follett, 1940; Pruitt, 1981; Walton \& McKersie, 1965). "Joint benefit" refers to the collective gain of the parties in the final

This research was supported by Grant BNS80-14902 from the National Science Foundation. The authors thank Dean Pruitt for his support and comments, and Michael Van Slyck for being the experimenter. Requests for reprints may be sent to Peter Carnevale. who is currently at the Department of Psychology, University of Illinois, Champaign, IL 61820. Alice M. Isen is currently at the University of Maryland Baltimore County. 
agreement. Understanding the conditions and processses that lead to or detract from the discovery of integrative solutions is important because integrative solutions to conflicts contribute to the long-term stability of relationships and to organizational effectiveness (Pruitt \& Carnevale, 1982).

Integrative solutions can be contrasted with "compromise," where concessions are made to a middle ground on some obvious dimension. The distinction between compromise and integrative solution can best be seen in situations where there are many possible solutions with different levels of joint benefit. Compared to other possible solutions, a compromise is a solution that only partly satisfies the two parties' interests; it is often the result of a simple and obvious decision scheme such as "split the difference." To illustrate the distinction between compromise and integrative solution, imagine two office workers arguing about the status of a window: one wants it open for fresh air, and the other wants it closed to reduce bothersome street noise. One solution, an obvious compromise, is to have it open half the day and closed the other half; each partly gets what she/he wants. A more integrative solution is to close the window in question and open a window in an adjacent room thereby reducing street noise while providing fresh air. Compared to the compromise solution, the integrative solution gives each more of what she/he wants. The task used in the present study involved a large number of negotiation alternatives of which only a few could satisfy both parties' interests. For each party to be successful, it was necessary that the pair search beyond the compromise alternatives and make mutually beneficial trade-offs.

Negotiators have four basic strategies available to them, three of which may lead to agreement (Pruitt, 1983; Pruitt \& Rubin, 1986): (1) problem solving, efforts to find an alternative that is acceptable to both parties; (2) contending or competitiveness, efforts to pursuade the other to accept alternatives that favor oneself; (3) yielding, a reduction in one's basic aspiration; and (4) inaction (avoidance), which may delay or even prevent agreement. These authors present a model of strategy selection that stems from Blake and Mouton's (1964) Managerial Grid and that has been adapted to the analysis of organizational conflict by others (Filley, 1975; Rahim, 1983; Ruble \& Thomas, 1976, Thomas, 1976). Another strategy, compromising, is mentioned by these other authors. However, if we view compromising as a weak form of problem solving, it may not be necessary to postulate a separate strategy to explain the development of compromise agreements (Pruitt, 1983).

The problem-solving strategy includes tactics such as the exchange of truthful information about needs and priorities, and a set of tactics referred to as "trial and error," involving (a) frequently changing one's offer; (b) seeking the other's reaction to each offer; (c) making larger concessions on items of lower priority; and (d) systematic concession 
making, where a negotiator explores various options at one level of value to himself/herself before proceeding to a lower level. The contending strategy includes tactics such as threats, positional commitments, contrived arguments designed to get the other to concede, and efforts to raise one's status in the other party's eyes. Past research (summarized in Pruitt, 1981) has found that contentious tactics interfere with the discovery of integrative solutions and that problem-solving tactics facilitate the discovery of integrative solutions (when yielding is prevented).

The present study was designed to examine the influence of positive affect on negotiation strategies and outcome. Positive affect has been shown to influence social behavior and judgment. For example, positive affect has been found to increase generosity and helpfulness (e.g., Isen, 1970; Isen \& Levin, 1972), to raise sociability (Isen, 1970), to enhance liking for others and improve conceptions of human nature (Gouaux, 1971; Veitch \& Griffitt, 1976), and to influence evaluations of a variety of stimuli in a positive direction (e.g., Isen, Shalker, Clark, \& Karp, 1978). Moreover, Baron and his associates have found that nonhostile humor can lessen aggressiveness (e.g., Baron, 1984; Baron \& Ball, 1974). Together these effects suggest that positive affect might reduce hostility and promote increased cooperativeness in negotiation; and, in fact. within negotiation contexts, there is evidence that mediators sometimes employ humor in their efforts to lighten hostile interactions (Carnevale \& Pegnetter, 1985).

Most recently, in addition, studies have shown that positive affect promotes integration and innovative solutions to problems (Isen, 1983; Isen \& Daubman, 1984; Isen, Johnson, Mertz, \& Robinson, 1985). These studies found that, relative to control groups, persons who had been made to feel good, in any of several ways, tended to group more stimuli together, to rate more stimuli as similar or as examples of the same categories, to give a broader range of associations to common words, to show increased recall of a subset of words that could be related to one another, and to be more likely to solve a problem requiring a creative view-a view involving seeing potential relationships among the elements of the problem. The authors interpreted these results as suggesting that positive affect promotes the tendency to integrate elements in problem solving and perhaps to take a broader view of the situation.

The ability or tendency to integrate elements in problem solving would seem to be central to successful performance in tasks such as the bargaining problem described above. The task requires making trade-offs in order to reconcile the parties' divergent interests, and the potential to see creative ways of combining the various elements might be necessary in order to achieve anything beyond the most obvious compromise. Thus, for two reasons, we expected positive affect to lead to more optimal 
integrative bargaining and negotiation outcome in the task described above: reduced hostility and increased integrative capacity.

In addition to positive affect, this study examined the influence of visual access on negotiation. Negotiators have visual access if they sit face to face across a table from one another; they do not have visual access if a physical barrier prevents them from seeing one another, or if the negotiations are conducted by telephone. Prior research (Carnevale, Pruitt, \& Seilheimer, 1981; Lewis \& Fry, 1977) has shown that bargainers who are not able to see one another are less likely to use contentious tactics, are more likely to see relationships among the issues such as trade-offs, and are more likely to discover integrative solutions.

These results suggest that the processes responsible for the effects of visual access and positive affect on bargaining outcome may be the same, namely, a reduction in the use of contentious tactics and an enhancement of integrative capacity. This has two implications for an experimental design that factorially crosses these factors. The first is that two main effects can be predicted, one for visual access and one for positive affect. Compared to visual access, the absence of visual access should result in lower levels of bargainer contentiousness, enhanced integration of issues (i.e., more trade-offs), and improved outcomes; this has been found in prior studies (Carnevale et al., 1981; Lewis \& Fry, 1977). Similarly, compared to affect control, positive affect should result in lower levels of contentiousness, enhanced integration, and improved outcomes, a hypothesis heretofore untested.

A second implication for an experimental design that crosses visual access/no visual access with positive affect/affect control is that there may be an interaction between these factors, since each factor may obscure the other in those conditions in which it is present. That is, if positive affect reduces contentiousness, enchances integrative capacity, and leads to improved outcomes, then a similar effect of visual isolation (no visual access) may not be observable under conditions of positive affect, because of the already optimal levels of outcome brought about by the other variable (positive affect). Also, if visual isolation reduces contentiousness, enhances integrative capacity, and leads to improved outcomes, then a similar effect of positive affect may not be observable because of the already optimal levels of outcome brought about by visual isolation. We did not expect the effects of these two factors to be additive, moreover, because we hypothesized the change in orientation and perception (reduced hostility and integration) underlying these effects to be categorical. That is, we view these effects to be a function of focus of attention or interpretation, which are discrete rather than continuous variables. Thus, we expected an interaction between affect and visual access, such that visual access would have no impact on negotiation outcome in 
the positive affect condition but would influence the process and impair the outcome of negotiation in the affect-control condition, and that positive affect would have no impact on outcome in the no-visual-access condition but would improve the process and outcome in the visual-access condition.

\section{METHOD}

\section{Subjects}

The subjects were 80 males recruited by advertisement on the campus of the State University of New York at Buffalo. They were promised and paid $\$ 4$ for their participation. Two subjects were employed in each session, making 40 dyads. Only dyads whose members were unknown to each other were allowed to participate.

Negotiation Task

The task closely resembled that used in previous research on integrative bargaining (Ben-Yoav \& Pruitt, 1984; Pruitt \& Carnevale, 1982). Subjects, as negotiators, played the roles of buyer and seller in a wholesale appliance market. They were instructed to try to reach agreement on the prices of three commodities: televisions, vacuum cleaners, and typewriters. Each subject was given a profit schedule with the instruction that it could not be shown to the other. In the buyer's schedule, TVs had the highest, and typewriters the lowest, profit potential. These priorities were reversed for the seller. Hence, the task permitted "logrolling," in the sense that both parties could achieve high profits by exchanging concessions on their low-profit items (see Fig. 1).

\section{Design and Procedure}

The basic experimental design involved two between-subjects factors. The two factors were visual access vs no visual access and positive-affect induction vs none (a control condition for the affect manipulation). Two

SELLER PROFIT SHEET
\begin{tabular}{|c|c|c|c|c|c|}
\hline Television Sets & \multicolumn{2}{|c|}{ Vacuum Cleaners } & \multicolumn{2}{|c|}{ Typewriters } \\
\hline Price & Profit & Price & Profit & Price & Profit \\
\hline A & $\$ 000$ & A & $\$ 000$ & A & $\$ 000$ \\
\hline B & $\$ 200$ & B & $\$ 300$ & B & $\$ 500$ \\
\hline C & $\$ 400$ & C & $\$ 600$ & C & $\$ 1000$ \\
\hline O & $\$ 600$ & D & $\$ 900$ & D & $\$ 1500$ \\
\hline E & $\$ 800$ & E & $\$ 1200$ & E & $\$ 2000$ \\
\hline F & $\$ 1000$ & F & $\$ 1500$ & F & $\$ 2500$ \\
\hline G & $\$ 1200$ & $G$ & $\$ 1800$ & $G$ & $\$ 3000$ \\
\hline$H$ & $\$ 1400$ & $H$ & $\$ 2100$ & $H$ & $\$ 3500$ \\
\hline I & $\$ 1600$ & I & $\$ 2400^{\circ}$ & I & $\$ 4000$ \\
\hline
\end{tabular}

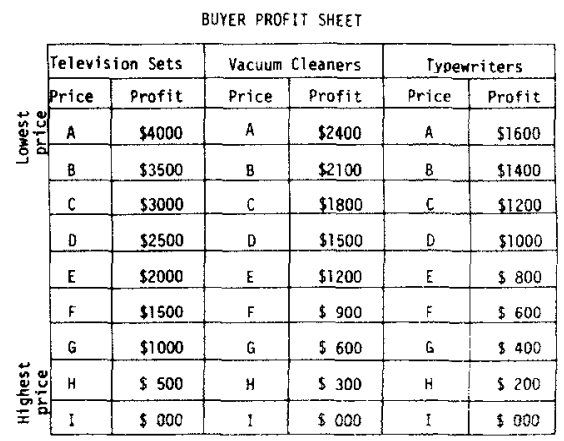

FIG. 1. Our integrative bargaining task (buyer and seller profit schedules). 
subjects were brought into the negotiation room at one time. The task was described as involving "negotiation between two simulated companies." The instructions were identical to those used by Lewis and Fry (1977) in their individualistic orientation conditions. The subjects were told to make as much profit for their company as possible, and they were each encouraged to make a minimum of $\$ 4600$.

In the no-visual-access conditions, a barrier that had separated the two subjects during the instructions remained in place for the negotiation. Thus, visual access was eliminated while verbal communication was not hindered. In the visual-access conditions, the barrier was removed for the negotiation, allowing the negotiators to see one another.

In the positive affect conditions, just before the negotiation was to begin, the subjects were told that something had gone wrong with the tape recorder that was to record the negotiation and that it would take about 5 min to repair it. While they were waiting, the experimenter asked them to rate some stimulus materials for an unrelated experiment that he was doing. These materials consisted of 30 cartoons of the "B.C." and New Yorker variety. The subjects were asked to sort them into two piles - those that were very funny and those not as funny. After the cartoons were sorted, the experimenter then continued with the final negotiation instructions. The experimenter gave each subject an $8 \times 11$ pad of paper to be used as a scratch pad. The subjects were told that they could keep the pad, that it was a gift. The subjects in the affectcontrol conditions did not see the cartoons nor receive the gift.

In all conditions, the experimenter sat in a room behind a one-way mirror during the negotiation. The experimenter operated a tape recorder that recorded the negotiation for later content analysis. Also behind the mirror were two observers whose task it was to monitor, using an event recorder, the visual behavior of the negotiators. This allowed the assessment of any direct relationships between nonverbal behaviors, such as staring, and the verbal tactics and outcome of negotiation. A time limit of $30 \mathrm{~min}$ was given for the negotiation. When the negotiation was over, the subjects completed a four-page questionnaire and were debriefed.

The first page of the questionnaire asked the subjects to report their mood using 18-point bipolar scales (e.g., pleasant-unpleasant, negativepositive). The second page contained questions that measured the negotiator's insight into the other party's priority preferences for the three items, something that Walton and McKersie (1965) have postulated contributes to the development of high joint benefit. If the respondent fully understood the order of importance to the other negotiator of the three appliances, a score of 2 was given. If the negotiator knew only the most important or the least important appliance to the other (but not both), a score of 1 was given. If the responses were totally incorrect, a score of 0 was given. These scores were multiplied by the respondent's confidence 
in answering this item, which was rated on a 4-point scale. The resulting index ranged from a low of 0 to a high of 8 . The third and fourth pages of the questionnaire contained items that assessed the subjects' perceptions of the tone of the negotiation and satisfaction with the outcome of the negotiation on 7-point scales. Ten dyads (negotiator pairs) were randomly assigned to each cell of the $2 \times 2$ design.

\section{RESULTS}

\section{Manipulation Checks}

Support was found for the manipulation of positive affect. Negotiators who were in the positive affect conditions reported that their mood was more positive, $F(1,36)=5.59, p<.03$, and more pleasant, $F(1,36)=$ $3.64, p<.07$, than did negotiators in the affect-control conditions. Positive affect also influenced the bargainers' perceptions of the tone of the interaction in the visual-access conditions. Subjects in a positive state rated the interaction as more informal, $F(1,18)=14.49, p<.001$; more helpful, $F(1,18)=11.22, p<.01$; closer, $F(1,18)=8.28, p<.01$; and less businesslike, $F(I, 18)=4.37, p<.05 .^{1}$ Because these measures were obtained following the negotiation, it is possible that the relationship between the affect manipulation and these measures was due to the more positive negotiation process and outcome that had occurred in the positive affect conditions. Evidence supporting this suggestion is the high correlation between the affect measures and satisfaction with the outcome of negotiation $(\bar{r}=.57)$. However, the measure of satisfaction with outcome was not affected by the mood manipulation, leading us to conclude that the relationship between the affect manipulation and affect measures is not due entirely to satisfaction with outcome.

\section{Outcome of the Negotiation}

The measure of negotiation outcome was the sum of the value of the agreement to the buyer and the seller. Table 1 shows this value for each cell of the design. Statistically significant main effects were found for both the visual-access factor and the mood factor. As can be seen in Row 1 of Table 1 , negotiators who were prevented from seeing one another achieved higher outcomes from the negotiation than negotiators who were able to see one another, $F(1,36)=10.27, p<.01$. Likewise, negotiators in whom positive affect had been induced achieved higher outcomes than negotiators not in a positive state, $F(1,36)=7.07, p<.02$. However, these main effects are qualified by a significant interaction. In support of the interaction hypothesis, visual access had no impact on joint outcome in the positive-affect condition, but did have such an effect in the controlaffect condition, $F(1,36)=16.9, p<.01$. When bargainers were face to

\footnotetext{
1 These ANOVA tests are simple-effect tests following up statistically significant interactions between the visual-access and affect factors.
} 
TABLE 1

Mean Negotiation Outcome and Process Measures as a Function of Affect AND Visual ACCESS

\begin{tabular}{|c|c|c|c|c|}
\hline \multirow[b]{2}{*}{ Measure } & \multicolumn{2}{|c|}{ Affect control } & \multicolumn{2}{|c|}{ Positive affect } \\
\hline & $\begin{array}{l}\text { Visual } \\
\text { access }\end{array}$ & $\begin{array}{l}\text { No visual } \\
\text { access }\end{array}$ & $\begin{array}{l}\text { Visual } \\
\text { access }\end{array}$ & $\begin{array}{l}\text { No visual } \\
\text { access }\end{array}$ \\
\hline Joint outcome $e^{a}$ & $8360(486)$ & $9950(453)$ & $9830(740)$ & $9650(972)$ \\
\hline Contentiuusness $^{b}$ & $0.52(0.30)$ & $-0.15(0.07)$ & $-0.18(0.21)$ & $-0.24(0.05)$ \\
\hline Trial and error ${ }^{b}$ & $-0.42(0.49)$ & $0.21(0.15)$ & $0.29(0.18)$ & $0.00(0.25)$ \\
\hline Insight $^{a}$ & $5.70(6.02)$ & $11.00(2.63)$ & $10.30(4.60)$ & $11.60(3.69)$ \\
\hline
\end{tabular}

Note. $n=10$ in each condition.

a Standard deviations in parentheses.

$b$ Variances in parentheses.

face, positive affect produced better outcomes $(t(18)=5.25, p<.01)$; when bargainers were not in a positive state, preventing them from seeing one another produced better outcomes $(t(18)=5.80, p<.01)$. This latter finding constitutes a replication of those of Lewis and Fry (1977) for a similarly constructed outcome measure. Similar interactions were obtained for the measures of negotiation process and are reported below.

\section{Verbal Process Measures}

The verbal process measures used in the present study were developed by content analyzing the tape recordings of the negotiations. The coding unit was a "statement" made by a negotiator, which was defined as anything said between the time that the other negotiator stopped speaking and started again. The same code could not be assigned to the same statement more than once. Each dyad received a score for each code consisting of the number of statements assigned to that code divided by the total number of statements made by the negotiators. Each code reflected one of the tactic categories mentioned in the introduction: for example, there was a code for "threats." Interrater reliabilities for this coding ranged above .77 (see Pruitt, 1981, for a detailed description of this coding system).

Table 1, row 2, shows the results for the use of contentious tactics in each of the four cells of the design. The measure reported here is an average of the standardized scores of the codes for threats, positional commitments, persuasive arguments, and put-downs. This category was modeled after Walton and Mckersie's (1965) description of distributive behavior. A threat was counted when a bargainer conveyed an intent to punish the other if the other failed to comply, e.g., "Agree to C on TVs or I take my business elsewhere." A positional commitment was counted when a bargainer stated an intent not to move from a position, e.g., " $\mathrm{C}$ 
on TVs is as low as I will go." A persuasive argument was counted when a bargainer mentioned extraneous issues in an attempt to persuade the other to concede, e.g., "Our TVs are the best you can buy anywhere." A put-down was counted when a bargainer negatively evaluated the other and derogated the other's status or power, e.g., "That offer is like leaving a dime tip for your waiter, more insulting than anything else."

Significant main effects were obtained for both the visual-access and affect factors: Negotiators who were able to see one another employed significantly more contentious tactics than those not able to see one another, $F(1,36)=8.75, p<.01$; and negotiators in whom positive affect had been induced employed significantly fewer contentious tactics, $F(1,36)=10.39, p<.01$. These main effects, however, are qualified by a significant interaction between the two factors. The negotiators who could see one another, and who wcre not in a positive feeling state, used more contentious tactics than the negotiators in the other conditions, $F(1,36)=6.23, p<.02$. Whereas positive affect reduced contentiousness in the visual-access condition $(t(18)=2.80, p<.01)$, this factor had no reliable effect for subjects who were not able to see one another $(t(18)=$ 0.78 , ns). Visual access enhanced contentiousness in the control-affect conditions $(t(18)=3.30, p<.001)$, but had no reliable effect for subjects in whom positive affect had been induced $(t(18)=0.36$, ns). As the reader will recall, results of the outcome of the negotiation mentioned earlier parallel those just reported: the negotiators in the visual-access/affectcontrol condition, who used the most contentious tactics, achieved the lowest outcomes.

Results for the trial-and-error index suggested a similar pattern. This index, an average of standardized scores of the number of alternatives proposed, number of requests for reactions to offers, number of systematic concessions, and number of concessions on low-priority items, has been found in prior research to reflect a cooperative negotiation process (Pruitt, 1981). A systematic concession was defined as any offer that provided a profit within $\$ 400$ of the same bargainer's previous offer and that involved a demand for greater profit on one item and less on another. A concession on a low-priority item was counted whenever an offer change involved a larger concession on the low-priority than on the highpriority item. The data on use of these cooperative tactics revealed a significant interaction between the two factors of this study. As shown in row 3 of Table 1 , the least use of these tactics occurred in the visualaccess/affect-control condition, $F(1,36)=8.14, p<.01$. Whereas positive affect enhanced the use of trial and error tactics in the visual-access condition $(t(18)=2.60, p<.01)$, this factor had no reliable effect for subjects who were not able to see one another $(t(18)=1.00, \mathrm{~ns})$. Visual access reduced trial and error tactics in the control-affect conditions $(t(18)$ 
$=2.33, p<.03$ ), but had no reliable effect for subjects in whom positive affect had been induced $(t(18)=1.32 p>.10)$. No significant effects were obtained for the composite index of truthful information exchange. However, bargainers who were face to face exchanged more priority information in the positive-affect condition than in the affect-control condition, $F(1,18)=5.24, p<.04$. Priority information exchange was counted when a bargainer compared the relative value of the items, e.g., "I'd rather have a higher price on TVs than on typewriters."

The bargainers were asked to indicate their understanding of the other's priority preferences for the three issues. As can be seen in row 4 of Table 1 , the lowest level of this variable is found in the face-to-face/affectcontrol condition. Although the interaction test was not statistically significant, $F(1,36)=2.06, p=.16$, there was a tendency for bargainers who were face to face to have greater insight in the positive-affect condition than in the affect-control condition, $F(1,18)=3.69, p<.07$, and those in the affect-control condition had greater insight in the non-visualaccess condition than in the visual-access condition, $F(1,18)=5.59, p$ $<.02$. These simple-effect tests support our proposition that positive affect, like the absence of visual access, enhances the capacity for integration.

\section{Nonverbal Process Measures}

As mentioned in the Method section, observers monitored the negotiators' nonverbal behaviors. A measure of the percentage of looking was constructed, which was the proportion of time the negotiators spent looking at one another during the negotiation. This measure was positively correlated with the use of contentious tactics, $r(18)=.38, p<.05$, and negatively correlated with the use of trial-and-error tactics, $r(18)=$ $-.39, p<.05$. This suggests that the use of the eyes in the negotiation context is competitive in nature and can be viewed as a nonverbal analog of a verbal contentious tactic. Although there was about half as much of this behavior in the positive-affect condition as in the affect-control condition $(9.8 \%$ vs $18.3 \%)$, this was not a statistically significant difference as revealed by analysis of variance, $F(1,18)=1.78, p=.19$. A closely related nonverbal index that was related to the affect manipulation was the mean proportion of time the bargainers spent not looking at one another and not speaking. This was greater in the positive-affect condition $(60 \%)$ than in the affect-control condition (45\%), suggesting that happy bargainers spend more time looking at their profit charts silently, $F(1,18)$ $=7.71, p<.01$. The more they did this, the less they used contentious tactics, $r(18)=-.60, p<.05$, and the more they used the cooperative trial-and-error tactics, $r(18)=.46, p<.05$. 


\section{DISCUSSION}

Lewis and Fry (1977) found that a physical barrier placed between competitively oriented bargainers led to a reduction in the use of dysfunctional contentious tactics and to an increase in the likelihood of integrative solutions; a barrier had no effect on cooperatively oriented bargainers. The present study replicates and extends these findings by reproducing the "barrier effect" and at the same time showing that the barrier has no effect on bargainers in whom positive affect has been induced. These results show, further, that positive affect can facilitate constructive, cooperative bargaining in face-to-face negotiations which would otherwise be marked by contentiousness and discord.

A physical barrier separating bargainers reduces the use of contentious tactics, increases integrative capacity, and leads bargainers to discover integrative solutions. Positive affect also appears to reduce the use of contentious tactics, to increase integrative capacity, and to lead bargainers to discover integrative solutions, even if the negotiators can see one another.

Lewis and Fry (1977) interpreted their findings in terms of visual contact and the role it plays in the perception of dominance. They argued that the perception of dominance is related to the use of contentious tactics, with these tactics being used in the hope of dominating one's opponent or in response to attempts by the other to dominate. Lewis and Fry assumed that the elimination of visual contact would make it more difficult to perceive dominance and thus a physical barrier would reduce the use of contentious tactics. The results of the present study support their assumptions. Furthermore, the results of the present study suggest that positive affect also reduces the perception of dominance. This proposition is consistent with prior research that showed that exposure to nonhostile humor reduced subsequent aggression (Baron, 1984; Baron \& Ball, 1974).

Lewis and Fry (1977) suggested that negotiators who spend time gazing at one another may communicate the impression that their intent is to dominate the other rather than to solve the problem, and that such an impression may lead to increased use of contentious tactics. Thus, they suggested that deliberate attempts to reduce eye contact might facilitate successful negotiation. As shown in the present study, these effects may also be alleviated if positive affect can be induced in the negotiators before the start of negotiations. In the visual-access conditions of the present study, positive affect reduced the proportion of time the bargainers spent looking at and speaking to one another. This suggests that positive affect may facilitate successful negotiation either by accomplishing that reduction in eye contact, or by otherwise reducing the per- 
ception that the other is attempting to dominate. These factors may also enhance integrative capacity, which may additionally facilitate successful negotiation.

The results of this study indicate that positive affect allows productive negotiation even when visual access is possible. In organizations, negotiation often must take place with visual access. Therefore, the use of positive affect may be a very useful tactic that may help negotiators discover optimal solutions.

These results also imply that basic cognitive processes, such as those recently found to be facilitated by positive affect (Isen, 1983; Isen \& Daubman, 1984; Isen et al., 1985) - those involved in categorization, similarity judgments, associations, and creative problem solving-are important in negotiation. The ability to integrate, to find creative ways of combining issues, and to develop novel solutions may be necessary for negotiators to achieve anything beyond obvious compromises. And these very abilities have recently been found to be enhanced by positive affect. Therefore, it may be for cognitive as well as social reasons that positive affect promotes integrative solutions in a bargaining situation, as we have found.

\section{REFERENCES}

Baron, R. A. (1984). Reducing organizational conflict: An incompatible response approach. Journal of Applied Psychology, 69, 272-279.

Baron, R. A., \& Ball, R. L. (1974). The aggression-inhibiting influence of nonhostile humor. Journal of Experimental Social Psychology, 10, 23-33.

Ben-Yoav, O. \& Pruitt, D. G. (1984). Accountability to constitutents: A two edged sword. Organizational Behavior and Human Decision Processes, 34, 283-295.

Blake, R. R., \& Mouton, J. S. (1964). The managerial grid. Houston: Gulf Publications.

Carnevale, P. J. D., \& Pegnetter, R. (1985). The selection of mediation tactics in publicsector disputes: A contingency analysis. Journal of Social Issues, 41, 65-81.

Carnevale, P. J. D., Pruitt, D. G., \& Seilheimer, S. (1981). Looking and competing: Accountability and visual access in integrative bargaining. Journal of Personality and Social Psychology, 40, 111-120.

Filley, A. C. (1975). Interpersonal conflict resolution. Glenview, IL: Scott, Foresman.

Follett, M. (1940). Constructive conflict. In H. Metcalf \& L. Urwick (Eds.), Dynamic administration. New York: Harper.

Gouaux, C. (1971). Induced affective states and interpersonal attraction. Journal of Personality and Social Psychology, 20, 37-43.

Isen, A. M. (1970). Success, failure, attention, and reactions to others: The warm glow of success. Journal of Personality and Social Psychology, 15, 294-301.

Isen, A. M. (1983). The influence of positive affect on cognitive organization. Paper presented at the Stanford Conference on Aptitude, Learning, and Instruction: Affective and Cognitive Processes.

Isen, A. M., \& Daubman, K. A.. (1984). The influence of affect on categorization. Journal of Personality and Social Psychology, 47, 1206-1217.

Isen, A. M., Johnson, M. M. S., Mertz, E., \& Robinson, G. F. (1985). The influence of positive affect on the unusualness of word associations. Journal of Personality and Social Psychology, 48, 1413-1426. 
Isen, A. M., \& Levin, P. F. (1972). Effect of feeling good on helping: Cookies and kindness. Journal of Personality and Social Psychology, 21, 384-388.

Isen, A. M., Shalker, T. E., Clark, M. S., \& Karp, L. (1978). Positive affect, accessibility of material in memory, and behavior: A cognitive loop? Journal of Personality and Social Psychology, 36, 1-12.

Lewis, S., \& Fry, W. (1977). Effects of visual access and orientation on the discovery of integrative bargaining alternatives. Organizational Behavior and Human Performance, 20, 75-92.

Pruitt, D. G. (1981). Negotiation behavior. New York: Academic Press.

Pruitt, D. G. (1983). Strategic choice in negotiation. American Behavioral Scientist, 27, $167-194$.

Pruitt, D. G., \& Carnevale, P. J. D. (1982). The development of integrative agreements. In V. Derlega \& J. Grzelak (Eds.), Cooperation and helping behavior: Theories and research. New York: Academic Press.

Pruitt, D. G., \& Lewis, S. (1975). Development of integrative solutions in bilateral negotiation. Journal of Personality and Social Psychology, 31, 621-633.

Pruitt, D. G., \& Rubin, J. Z. (1986). Social conflict: Escalation, stalemate, settlement. New York: Random House.

Rahim, M. A. (1983). A measure of styles of handling interpersonal conflict. Academy of Management Journal, 26, 368-376.

Ruble, T. L., \& Thomas, K. W. (1976). Support for a two-dimensional model of conflict behavior. Organizational Behavior and Human Performance, 15, 143-155.

Thomas, K. W. (1976). Conflict and conflict management. In M. D. Dunnette (Ed.), Handbook of industrial and organizational psychology. Chicago: Rand McNally.

Veitch, R., \& Griffitt, W. (1976). Good news-bad news: Affective and interpersonal effects. Journal of Applied Social Psychology, 6, 69-75.

Walton, R. E., \& McKersie, R. B. (1965). A behavioral theory of labor negotiations. New York: McGraw-Hill.

RECEIVED: April 12, 1984 